\title{
PREJUÍZOS CAUSADOS PELA MASTITE EM OVELHAS SANTA INÊS
}

\author{
C.J. Veríssimo ${ }^{1}$, L.F. Zafalon ${ }^{2}$, I.P. Otsuk ${ }^{1}$, A.F.C. Nassar $^{3}$ \\ ${ }^{1}$ Instituto de Zootecnia, CP 60, CEP 13460-000, Nova Odessa, SP, Brasil. E-mail: cjverissimo@iz.sp.gov.br
}

\author{
RESUMO
}

\begin{abstract}
A mastite tem causado grandes prejuízos em criações de ovinos para corte no Brasil, onde o número de cordeiros nascidos e desmamados é de enorme importância econômica para o sistema de produção. O objetivo deste trabalho foi quantificar esses prejuízos em uma propriedade com ovinos da raça Santa Inês, em sistema semi-intensivo de produção, no Estado de São Paulo. Foram feitos exames clínicos, o Califórnia Mastitis Test (CMT), e as colheitas de leite para exame microbiológico das ovelhas na segunda semana de parição e no desmame. No mesmo dia das colheitas de amostras de leite, os cordeiros foram pesados, bem como no dia do nascimento. Quarenta e uma ovelhas pariram 55 cordeiros (taxa de natalidade 1,34) na estação de parição de 23/10/2008 a 4/1/2009. Destes, 20 (36\%) morreram, 14 (70\%) nas primeiras duas semanas de vida, e seis (30\%) antes do desmame, que ocorreu em torno de 70 dias. 70\% (14) das mortes foram atribuídas à condição de mastite da ovelha, e 30\% (6) a outras causas, principalmente pneumonia. O ganho de peso diário do nascimento ao desmame de cordeiros filhos de ovelhas com mastite, em pelo menos uma glândula mamária, foi inferior $(\mathrm{P}<0,10)$ ao de cordeiros filhos de ovelhas sadias. Das amostras positivas no exame microbiológico, $85,8 \%$ estavam positivas para bactérias do gênero Staphylococcus.
\end{abstract}

PALAVRAS-CHAVE: Cordeiros, desempenho, mastite, mortalidade, Staphylococcus.

\section{ABSTRACT}

DAMAGES CAUSED BY MASTITIS IN SANTA INÊS BRAZILIAN SHEEP BREED. In meat sheep herds in Brazil, mastitis has provoked many damages, causing mortality and decreasing the numbers of lambs born and weaned, posing heavy economic impacts for the production system. The objective of this study was to quantify the damages caused by mastitis in a Santa Inês breed herd, reared in a semi-intensive production system, in São Paulo State, Brazil. Clinical exams were conducted and the California mastitis test was carried out, and milk samples were taken from the ewes for microbiological assay. The lambs were weighed at birth and on the days when the milk samples were taken. Forty-one ewes gave birth to 55 lambs (birth rate of 1.34) during the parturition season from 23 October 2008 to 4 January 2009. Twenty (36\%) of them died, 14 (70\%) in the first 2 weeks following birth, and $6(30 \%)$ before weaning, which occurs at about 70 days. A total of $70 \%$ (14) of the deaths were imputed to the occurrence of mastitis in the respective ewe, and $30 \%$ (6) to other causes, mainly pneumonia. Mastitis decreased the average daily gain of the lambs from birth to weaning $(\mathrm{P}<0.10)$. Most of the positive microbiological samples $(85.8 \%)$ where positive for Staphylococcus spp.

KEY WORDS: Lambs, mastitis, mortality, performance, Staphylococcus.

\section{INTRODUÇÃO}

Mastite ou mamite é a inflamação da glândula mamária, que afeta a produção (GoNZALo et al., 2002) e a qualidade do leite das ovelhas (BuRRIEL, 1997), o que se reflete no desempenho dos cordeiros e sua viabilidade. Existe, ainda, a possibilidade de morte de fêmeas devido à mastite gangrenosa (VAZ, 1996; SANTOS et al., 2007), ou perda de uma das glândulas em consequência da mastite clínica (OliverRa et al., 2007), o que leva ao descarte, muitas vezes precoce, de ovelhas que podem pertencer a alta linhagem genética, com consequente desvalorização de seu valor comercial, além de custo elevado com mão-de-obra, honorários profissionais e medicamentos (WINTER, 2001). MADEL (1981), observando 1.650 ovelhas abatidas na Inglaterra, concluiu que anormalidades nas glândulas mamárias foram importantes razões para o descarte das fêmeas.

${ }^{2}$ Embrapa Pecuária Sudeste, São Carlos, SP, Brasil.

${ }^{3}$ Instituto Biológico, Centro de Pesquisa e Desenvolvimento de Sanidade Animal, São Paulo, SP, Brasil. 
Em outros países, os prejuízos causados pela doença, com impactos no desempenho e mortalidade de cordeiros, já são bem conhecidos (FTHENAKIS; Jones, 1990; Larsgard; VaAbenoe, 1993; Arsenault et al., 2008).

No Brasil, a mastite ocasionada principalmente por bactérias do gênero Staphylococcus vem causando grandes prejuízos (SANTOS et al., 2007), e sua ocorrência é relatada em muitos estados do país, tais como Pernambuco (Oliveira et al., 2007), Sergipe (Oliveira, 2006; Melo et al., 2008), Bahia (CoutinHo et al., 2006; Alvares et al., 2007), São Paulo (Hernandes; LucheIs, 2006; Nunes et al., 2008), Rio Grande do Sul (FERnANDES; CARDOSO, 1985; VAZ, 1996), porém, os prejuízos produzidos pela doença no desempenho e na viabilidade dos cordeiros ainda não estão bem estabelecidos.

A ovinocultura de corte vem tendo grande expansão como agronegócio em todo o país. A criação da raça ovina de origem brasileira Santa Inês tem sido incentivada por técnicos como raça matriz ideal para cruzamentos com reprodutores de raças especializadas para o corte, visando obter cordeiros para o abate precoce, devido à sua rusticidade e adaptabilidade ao clima quente dos trópicos, além de apresentar outras vantagens, tais como ser deslanada e não precisar de tosquia ou corte de cauda, apresentar cio em qualquer época do ano, ser menos suscetível a ecto e endoparasitos, ter menor incidência de problemas de casco, ser prolífica e possuir boa habilidade materna. (VERíssimo et al., 2002).

Devido ao fato de que na formação da raça entraram animais da raça Bergamácia, de potencial leiteiro (SANTOS, 2003), a Santa Inês também apresenta grande potencial de produção leiteira (FERREIRA et al., 2007), o que, certamente, contribui para aumentaros problemas com a mastite, já que Cruz et al. (1994) verificaram que a probabilidade decasos demastitesubclínica aumenta emovelhascommaior produçãoleiteira.SegundoMELO et al. (2008), as ovelhas Santa Inês apresentam longo período delactação, fato esse quefavorece a ocorrência de mastite, pois, após a desmama, o úbere pode permanecercomleiteresidual, havendoa possibilidadede crescimento bacteriano, uma vez que oleiteé excelente meio de cultura (JONES; LANYON, 1990).

Visandoalertar produtores, técnicose autoridades sanitárias sobre a importância econômica da mastite em ovinos de corte foi elaborado o presente trabalho, com o objetivo de quantificar, em um rebanho com histórico da doença, o impacto no ganho de peso e na mortalidade de cordeiros da raça Santa Inês.

\section{MATERIAL E MÉTODOS}

O trabalho foi realizado no Estado de São Paulo, em uma propriedade que utiliza manejo semi-intensivo de produção. Foram observadas 41 ovelhas da raça Santa Inês com intervalo de parição entre 23/10/2008 a 4/1/2009. As ovelhas eram confinadas em baias com suas crias assim que pariam, e ali ficavam nas primeiras duas semanas de vida do cordeiro, a fim de criar vínculo entre mãe e filho. Após esse período, os animais foram transferidos para o sistema de semiconfinamento, onde havia dois cochos comuns, com $15 \mathrm{~m}$ de linha de cocho, cobertos, dentro de uma área de cerca de $700 \mathrm{~m}^{2}$, com livre acesso. A alimentação das ovelhas era fornecida duas vezes por dia, e composta por silagem de milho $(7 \%$ de proteína bruta, $\mathrm{PB})$, à vontade, $\mathrm{e}$ concentrado, formulado na propriedade com 18\% $\mathrm{PB}$, cerca de $0,5 \mathrm{~kg}$ de concentrado/cabeça/dia. Os cordeiros, a partir de 15 dias de vida, tinham acesso a "creepfeeding" com concentrado com 18\% PB. O rebanho apresentava histórico de mastite (VERíssimo et al., 2003; Veríssimo et al., 2007).

Duas semanas após a parição, e no desmame, foram feitas colheitas de amostras de leite e pesagens dos cordeiros. Estes foram pesados, também, logo após o nascimento. No dia da primeira colheita, os cordeiros foram separados das mães às $9 \mathrm{~h}$, pesados em seguida, e o exame nas ovelhas foi realizado às $13 \mathrm{~h}$. No dia do desmame, os cordeiros foram separados das mães pela manhã, pesados, e o exame das ovelhas realizado à tarde. Os cordeiros foram desmamados, em média, aos $73 \pm 10$ dias de idade.

Antes de cada colheita de leite, as ovelhas foram submetidas a exame clínico da glândula mamária. No examefísico, as metades mamárias foramexaminadas por inspeção e palpação. Na palpação, as mamas foram classificadas quantoà consistência, conformeos critérios adotados por BlAGITZ et al. (2007): consistência normal, consistência macia com nódulos pequenos, consistência macia com nódulos endurecidos, consistência firme, consistência firme com nódulos grandes, econsistência firme difusa (totalmente duro). Após o exame físico da glândula mamária, foram retiradas amostras de leite para o exame CMT (SCHALM; NOORLANDER, 1957) e bacteriológico.

Antes daretirada doleitedecada glândula mamária, realizava-se pré-dipping, secagem do teto com papel toalha e, finalmente, a antissepssia para a colheita das amostras de leite com algodão embebido em álcool $70^{\circ} \mathrm{GL}$ no óstio do teto. Em dois dos quatro compartimentos da caneca do teste CMT eram direcionados os três primeiros jatos de leite de cada glândula mamária, de modo a se verificar as características do leite da ovelha (coloração, viscosidadeou gelificação, presença de grumos, sangue e pus). Em seguida, nos outros dois compartimentos não utilizados anteriormente, correspondendo a cada glândula, eram adicionados $2 \mathrm{~mL}$ de leite e $2 \mathrm{~mL}$ do reagente CMT. Logo após o exame CMT, foram colhidos, de cada glândula, aproximadamente $10 \mathrm{~mL}$ de leite, em duplicata, em tubos estéreis 
devidamenteidentificados, paraexamemicrobiológico. As amostras foram congeladas e, posteriormente, encaminhadas ao laboratório de microbiologia da Embrapa PecuáriaSudeste, localizada emSão Carlos, para análisemicrobiológica. Nolaboratório, foramsemeados 10 microlitros das amostras de leite em ágar base enriquecidocom $5 \%$ desanguedecarneiro, incubandoem estufa bacteriológica a $37^{\circ} \mathrm{C}$, com leituras após 24,48 e 72 horas. Após o período de incubação, se houvesse proliferação bacteriana nesse meio, as características decrescimento ehemólise foram observadas. A seguir, foi realizada a bacterioscopia, corando-se pelo método de Gram. As espécies bacterianas foram identificadas de acordo com HARMON et al. (1990), Holt et al. (1994), Koneman et al. (2001) e ZafaLon (2003).

Para determinar o impacto da mastite no ganho dos cordeiros, as ovelhas foram separadas em três grupos: 1) sadias (sem mastite nas duas glândulas mamárias); 2) mastite crônica e/ou subclínica (aquelas que apresentassem ao exame físico do úbere pelo menos uma das glândulas mamárias com consistência macia com nódulos endurecidos e/ou consistência firme com nódulos grandes, e/ ou apresentassem CMT positivo (++), e/ou CMT positivo $(+++)$, e/ ou positivo para o isolamento de bactérias, mas não apresentassem sinais de mastite clínica;3) mastite clínica (aquelas que apresentassem alterações evidentes no leite (grumos, presença de sangue, pus ou soro), ou no úbere (úbere totalmente duro, sem secreção láctea ou com sinais de rubor, calor, edema ou dor). As ovelhas com mastite clínica foram tratadas com antimicrobianos.

Para a análise do ganho de peso diário dos cordeiros foi utilizado o delineamento inteiramente ao acaso, com diferentes repetições, onde foram estudados os efeitos de sexo do cordeiro (macho ou fêmea), tipo de parto (simples ou múltiplo), ordem do parto da ovelha (primíparas ou multíparas) e efeito da mastite (sem mastite, com pelo menos uma glândula com mastite crônica e/ou subclínica, e com pelo menos uma glândula com mastite clínica). O nível de significância adotado para a análise de variância foi de $10 \%$. Para fins de análises estatísticas, as variáveis foram transformadas em Raiz de $\mathrm{X}$ para atendimento das pressuposições do modelo matemático. Na tabela do Ganho de Peso Diário (Tabela 2) são apresentadas as médias originais, com os testes de comparação de médias baseados na análise de dados transformados. As interações dos efeitos principais não foram considerados, por não apresentarem efeitos significativos.

\section{RESULTADOS E DISCUSSÃO}

As 41 ovelhas pariram 55 cordeiros (taxa de natalidade 1,34). Destes, 20 (36\%) morreram, 14 (70\%) nas primeiras duas semanas de vida, e seis (30\%) no período seguinte até o desmame, que ocorreu, em média, aos $73 \pm 10$ dias. Catorze mortes (70\%) foram atribuídas à condição de mastite da ovelha, e $30 \%$ (6) a outras causas, principalmente pneumonia. Verifica-se (Tabela 1) que as ovelhas sem mastite desmamaram percentualmente mais cordeiros, já as ovelhas com mastite clínica tiveram alta taxa de mortalidade de cordeiros (75\%), principalmente nas duas primeiras semanas pós-parto, ocasião em que é grande a correlação entre o ganho de peso do cordeiro e a quantidade de leite ingerida (BuRRIS; BAUgus, 1955). As ovelhas com mastite crônica e/ou subclínica ficaram com porcentagens intermediárias, tiveram maior número de óbitos que as sem mastite, mas esse número foi bem inferior ao observado para as com mastite clínica. Igualmente, desmamaram, percentualmente, uma quantidade de cordeiros menor $(74,07 \%)$ do que as sem mastite $(81,25 \%)$, mas bem superior às com mastite clínica $(16,66 \%)$.

Das 41 ovelhas que pariram eforam observadas no início da lactação, 11 (26,8\%) não tinham mastite em nenhuma das glândulas, 20 (48,7\%) tinham mastite crônica ou subclínica em pelo menos uma das glândulas e $10(24,5 \%)$ tinham mastite clínica em pelo menos uma das glândulas. Das 10 ovelhas que apresentaram sinais de mastite clínica no início da lactação, nove foram tratadas com antimicrobianos (22\% do total de ovelhas): uma antes do parto (cerca de duas semanas antes), sete logo após o parto (dentro das primeiras duas semanas de parição), e uma no meio da lactação (aos 47 dias de parição). Emuma ovelha, cuja glândula esquerda havia sido tratada três dias seguidos com $150 \mathrm{mg}$ de gentamicina intramamária, indicado para vacas em lactação, logo após o parto, constatou-se que houve a perda da referida glândula (sem secreção láctea e totalmente duro) no desmame. A maioria das ovelhas que perdeu cordeiros por causa da mastite (9/10,90\%) apresentava mais dequatroanos deidade; cinco delas $(50 \%)$ pariram com glândulas mamárias perdidas, quatro com uma e uma com as duas perdidas. Veríssimo et al. (2003), observando a ocorrência de mastite clínica em uma estação de parição no ano de 2003, no mesmo rebanho deste trabalho, verificaram que entre ovelhas das raças Santa Inês, Ile de France e Suffolk houve maior número de casos nas ovelhas da raça Santa Inês; dois casos de mastite gangrenosa foram observados na raça Ile de France, um deles com óbito, egrandefrequência de Staphylococcus sp. (65\%), nos isolamentos efetuados. Veríssimo et al. (2007), estudando as ocorrências de mastite em outra estação de parição do mesmo rebanho, constataram, inclusive, casos de mastite clínica em fêmeas primíparas Santa Inês, onde, novamente, foi grande a frequência de isolamentos de Staphylococcus sp., em várias raças criadas no rebanho (Santa Inês, Morada Nova, Ile de France, Suffolk e Texel). 
Tabela 1 - Mortalidade de cordeiros filhos de ovelhas com e sem mastite, de acordo com o período em que morreram, e número de cordeiros desmamados.

\begin{tabular}{|c|c|c|c|c|}
\hline Ovelhas & $\begin{array}{l}\text { Óbitos cordeiros } \\
\text { Nasc-14dias }\end{array}$ & $\begin{array}{l}\text { Óbitos cordeiros } \\
\text { 14d-desmame }\end{array}$ & $\begin{array}{l}\mathrm{N}^{\circ} \text { cordeiros } \\
\text { desmamados }\end{array}$ & Total \\
\hline Sadias & $1(6,25 \%)$ & $2(12,5 \%)$ & $13(81,25 \%)$ & 16 \\
\hline $\begin{array}{l}\text { Mastite crônica e/ou subclínica em pelo menos uma } \\
\text { das glândulas mamárias }\end{array}$ & $4(14,82 \%)$ & $3(11,11)$ & $20(74,07 \%)$ & 27 \\
\hline $\begin{array}{l}\text { Mastite clínica em pelo menos uma das glândulas } \\
\text { mamárias }\end{array}$ & $9(75 \%)$ & $1(8,33 \%)$ & $2(16,66 \%)$ & 12 \\
\hline
\end{tabular}

FERNANDES; CARDOSO (1985), estudando um surto de mastite em um rebanho da raça Hampshire Down, verificaram que, das 80 ovelhas examinadas, oito $(10 \%)$ apresentaram mastite clínica e sete $(8,75 \%)$ fibrose da glândula mamária, e Staphylococcus aureus foi isolado de todas as amostras enviadas ao laboratório. Os autores administraram antimicrobianos para uso em vaca seca, tal como fez Hendy et al. (1981), e na lactação seguinte não foram observadas, em nenhum dos animais tratados, alterações na glândula mamária. Meloet al. (2008) também instituíram uma antibioticoterapia no desmame que foi favorável ao controle da mastite clínica em ovelhas da raça Santa Inês, em observações feitas ainda durante o período seco.

Oliveira et al. (2007) estudaram 31 rebanhos de ovinos da raça Santa Inês (135 ovelhas) localizados em 15 municípios na região do Agreste Meridional do Estado de Pernambuco, Brasil, e verificaram mastite clínica em $15,5 \%$ das ovelhas, a maioria (76\%) com comprometimento unilateral, e o restante de forma bilateral, totalizando 9,63\% glândulas mamárias comprometidas. Os autores verificaram que os sinais clínicos mais frequentes nas mastites clínicas foram o aumento de volume e fibrose e, também, foram diagnosticadas mastites gangrenosas em $9,52 \%$ das ovelhas. Staphylococcus aureus foi isolado com maior frequência (38,8\%), seguido de Staphylococcus coagulase negativo (SCN) $(33,33 \%)$.

SANTOS et al. (2007) inocularam um dos tetos de ovelhas sadias com uma cepa de $S$. aureus, isolada no Estado de Pernambuco, e constataram altíssima patogenicidade dessa cepa.

Observando-se a Tabela 2, verifica-se que o sexo docordeironão teve influência sobreo ganho de peso diário, tal como verificado por TORRES-HERNANDEZ; HoHENBOKEn (1980) e Mexia et al. (2004). Já, o tipo de parto influenciou $(\mathrm{P}<0,10)$ o ganho de peso dos cordeiros, pois os provenientes de parto duplo tiveram menores ganhos em todos os períodos observados, concordando com os achados de TORRES-HERNANDEZ; HoHENBOKen (1980) e Mexia et al. (2006). Não foi observado efeito da ordem do parto no ganho de peso dos cordeiros, ao contrário do que constataram RoDA et al. (1995), que observaram menor ganho de peso em cordeiros filhos de ovelhas de primeira cria, em relação a fêmeas com mais de uma parição, com exceção das idosas (mais de sete anos).

Quanto ao efeito da mastite sobre o ganho de peso diário dos cordeiros (Tabela 2), a forma clínica influenciou negativamente o ganho de peso do cordeiro, em todos os períodos observados, e a crônica e/ou subclínica não chegou a influenciar no ganho de peso dos cordeiros nas duas primeiras semanas de vida, mas diferença significativa $(\mathrm{P}<$ $0,10)$ foi observada quando foram considerados os períodos de 14 dias até o desmame, e o período total, do nascimento ao desmame.

O consumo de leite é muito importante para o ganho de peso do cordeiro, principalmente nas primeiras quatro semanas pós-parto (BURRIS; BAUGUS, 1955). Leite proveniente de ovelhas com mastite fica com seus constituintes alterados (BurRIEL, 1997), o que vai refletir negativamente no desempenho do cordeiro (FTENAKIS; JONES, 1990; LARSGARD; VAabenoe, 1993; Arsenault et al., 2008). Arsenault et al. (2008) também verificaram que a incidência de mastite clínica estava associada a aumento na mortalidade de cordeiros e ovelhas, e a incidência da doença foi maior em ovelhas com idade igual ou superior a quatro anos, tal como observado neste estudo. GonZALO et al. (2002) verificaram que pode haver perdas na produção de leite entre 8,8 a 10,1\%, em fêmeas ovinas de raças leiteiras (Churra), com mastite subclínica, infectadas, a maioria com SCN. LARSGARD; VAABENOE (1993) verificaram que a incidência de mastite aumentava conforme a ordem de parição da ovelha. Houve efeito de raça sobre a incidência de mastite, e ovelhas com os piores escores para formato de úbere também foram mais suscetíveis; a mastite influenciou o ganho de peso dos cordeiros, diminuindo-o. Os autores observaram que a maioria dos casos severos de mastite ocorreu logo após o parto, tal como observado neste trabalho. Entretanto, KEISLER et al. (1992) não encontraram efeito da mastite subclínica no desempenho de cordeiros de raças de ovinos de corte que tinham acesso à alimentação suplementar por meio de "creepfeeding", a partir da primeira semana de idade. 
Tabela 2 - Médias de ganho de peso diário do nascimento aos 14 dias, dos 14 dias ao desmame e do nascimento ao desmame, de cordeiros filhos de ovelhas com e sem mastite.

\begin{tabular}{|c|c|c|c|c|c|c|c|}
\hline \multirow[b]{2}{*}{ Efeito } & & \multicolumn{6}{|c|}{ Ganho de peso diário (kg) } \\
\hline & & $\mathrm{N}$ & $\begin{array}{l}\text { Nascimento } \\
\text { aos } 14 \text { dias }\end{array}$ & $\mathrm{N}$ & $\begin{array}{l}14 \text { dias ao } \\
\text { desmame }\end{array}$ & $\mathrm{N}$ & $\begin{array}{l}\text { Nascimento } \\
\text { ao desmame }\end{array}$ \\
\hline \multirow{2}{*}{ Sexo } & Macho & 16 & $0,12 \mathrm{a}$ & 14 & $0,12 \mathrm{a}$ & 14 & $0,12 \mathrm{a}$ \\
\hline & Fêmea & 24 & $0,11 \mathrm{a}$ & 20 & $0,10 \mathrm{a}$ & 21 & $0,11 \mathrm{a}$ \\
\hline Tipo de & Simples & 24 & $0,15 a$ & 19 & $0,12 \mathrm{a}$ & 20 & $0,13 a$ \\
\hline Parto & Duplo & 16 & $0,09 \mathrm{~b}$ & 15 & $0,09 b$ & 15 & $0,09 b$ \\
\hline Ordem do & Primípara & 5 & $0,10 \mathrm{a}$ & 5 & $0,16 a$ & 5 & $0,11 \mathrm{a}$ \\
\hline \multirow{2}{*}{ Parto } & Multípara & 35 & $0,13 a$ & 29 & $0,10 \mathrm{a}$ & 30 & $0,12 \mathrm{a}$ \\
\hline & Sem mastite & 14 & $0,13 a$ & 12 & $0,16 a$ & 13 & $0,16 \mathrm{a}$ \\
\hline \multirow[t]{2}{*}{ Mastite } & $\begin{array}{l}\text { Crônica e/ou subclínica em pelo menos uma } \\
\text { das glândulas }\end{array}$ & 22 & $0,14 \mathrm{a}$ & 20 & $0,12 \mathrm{~b}$ & 20 & $0,12 b$ \\
\hline & Clínica em pelo menos uma das glândulas & 4 & $0,02 \mathrm{~b}$ & 2 & $0,05 c$ & 2 & $0,06 \mathrm{c}$ \\
\hline \multicolumn{2}{|c|}{ Média Geral } & & 0,16 & & 0,12 & & 0,13 \\
\hline \multicolumn{2}{|l|}{$\mathrm{CV} \%$} & & 11,51 & & 14,73 & & 13,90 \\
\hline
\end{tabular}

Médias seguidas de letras diferentes nas colunas diferem entre si pelo teste F para os efeitos Sexo, Tipo de Parto e Ordem de Parição, e pelo teste de Tukey para o efeito Mastite $(\mathrm{P}<0,10)$.

CV\% - coeficiente de variação para dados transformados.

Tabela 3 - Exame físico da glândula mamária, realizado em ovelhas Santa Inês, aos 14 dias de parida e no desmame.

\begin{tabular}{lcc}
\hline Exame físico do úbere & Início lactação & Final lactação \\
\hline Normal & $39(48,75 \%)$ & $50(78,12 \%)$ \\
Macio com nódulos pequenos & $12(15 \%)$ & $10(15,62 \%)$ \\
Macio com nódulos endurecidos & $13(16,25 \%)$ & $3(4,7 \%)$ \\
Firme & $2(2,5 \%)$ & - \\
Firme com nódulos grandes & $5(6,25 \%)$ & - \\
Totalmente duro & $9(11,25 \%)$ & $1(1,56 \%)$ \\
\hline
\end{tabular}

Tabela 4 - Aspecto do leite em glândulas mamárias de ovelhas Santa Inês no início e final da lactação.

\begin{tabular}{lcc}
\hline Leite & $\begin{array}{c}\text { Início } \\
\text { lactação }\end{array}$ & $\begin{array}{c}\text { Final } \\
\text { lactação }\end{array}$ \\
\hline Normal & $67(83,75 \%)$ & $54(84,37 \%)$ \\
Com grumos & $5(6,25 \%)$ & $1(1,56 \%)$ \\
Consistência espessa (pus) & $1(1,25 \%)$ & $1(1,56 \%)$ \\
Consistência serosa & - & $3(4,7 \%)$ \\
Com sangue (leite rosado) & - & $1(1,56 \%)$ \\
Sem leite & $7(8,75 \%)$ & $4(6,25 \%)$ \\
\hline
\end{tabular}

De um total de 80 glândulas mamárias avaliadas no início da lactação, verificou-se que $39(48,75 \%)$ estavam macias à palpação (Tabela 3), e 41 (51,25\%) apresentavam alguma anormalidade. De um total de 64 glândulas avaliadas no desmame, 50 (78,12\%) estavam normais à palpação (Tabela 3$)$ e $14(21,88 \%)$ apresentavam algum nódulo. VAZ (1996) verificou alta frequência de lesões no úbere em determinadas propriedades, e aconselhou o exame do úbere antes da cobertura, seguido do descarte daquelas com lesões que possam prejudicar a produção de leite, e, consequentemente, comprometer a sobrevivência ou o desenvolvimento do cordeiro.

Quanto ao aspecto do leite (Tabela 4), verificase que a porcentagem de animais que não tiveram secreção de leite na primeira colheita $(8,75 \%)$ foi maior do que na segunda colheita (6,25\%). De cinco ovelhas que pariram com pelo menos uma das glândulas mamárias perdidas, apenas uma desmamou a cria (parto simples). A maioria das ovelhas que não apresentou leite na primeira avaliação em uma das glândulas secou nas primeiras semanas pós-parto, devido à morte de seu(s) cordeiro(s). Na segunda colheita (desmame), todas as ovelhas que não tiveram produção de leite foram positivas no exame físico da glândula mamária, apresentando algum tipo de nódulo, o que é indicativo de que houve algum processo infeccioso crônico na glândula durante esta ou na lactação anterior, que diminuiu a produção leiteira na glândula mamária afetada. 
Tabela 5 - Diagnóstico de mastite pelo teste CMT em ovelhas Santa Inês

\begin{tabular}{lcc}
\hline Resultado do CMT & Início lactação & Desmame \\
\hline Negativo & $35(43,75 \%)$ & $29(46,03 \%)$ \\
$(+)$ & $12(15 \%)$ & $8(12,69 \%)$ \\
$(++)$ & $6(7,5 \%)$ & $4(6,34 \%)$ \\
$(+++)$ & $15(18,75 \%)$ & $17(27,01 \%)$ \\
Mastite clínica* & $5(6,25 \%)$ & $1(1,58 \%)$ \\
Sem leite & $7(8,75 \%)$ & $4(6,35 \%)$ \\
\hline
\end{tabular}

*alterações macroscópicas no leite.

Hueston et al. (1989) afirmaram que a existência de infecção intramamária em uma glândula mamária aumenta significativamente o risco de infecção na outra glândula, e o tratamento das glândulas mamárias no final da lactação (desmame dos cordeiros) teve alta taxa de cura de infecções preexistentes nas ovelhas.

Com relação ao resultado do teste CMT (Tabela5), a porcentagem de glândulas mamárias negativas foi muito semelhanteà de glândulas mamárias positivas, tanto no início da lactação (43,75\% negativose $41,25 \%$ positivos) quanto no desmame $(46,03 \%$ negativos e $46,04 \%$ positivos). NunEs et al. (2008) concluíram que o CMT, a contagem de células somáticas e o conteúdo de cloretos são ferramentas confiáveis para o diagnóstico da mastite ovina. Dentre estes, o CMT é um exame barato, de fácil execução, e pode ser realizado na propriedade. BARBOSA et al. (2004) também concluem que o CMT é um bom indicador da presença ou ausência de infecção nos escores $(+++)$ e (-), respectivamente. Numérica e percentualmente foi observado aumento de CMT (+++) ao desmame (Tabela 5). Blagitz et al. (2004), utilizando CMT e contagem de células somáticas, também observaram em ovelhas Santa Inês maior número de células somáticas no desmame, sem que isto implicasse em aumento de isolamentos de patógenos.

Verifica-se na Tabela 6 que as bactérias mais isoladas neste trabalho pertenceram ao gênero Staphylococcus: Staphylococcus spp. coagulase negativo $(64,3 \%)$, Staphylococcus spp. coagulase positivo $(17,9 \%)$ e $S$. aureus $(3,6 \%)$. Esse gênero tem sido frequentemente isolado em ovinos da raça Santa Inês no Brasil (COUTINHO et al., 2006; RICCIARDi et al., 2007; BLAGITZ et al., 2008), assim como em outras raças criadas em vários países do mundo (KeISLER et al., 1992; SARATSIs et al., 1999; BERGONIER et al., 2003, BOLSANELLO et al., 2009). Essas bactérias, segundo Hueston et al. (1989), BERGONIER et al. (2003) e Contrerasetal. (2007), são a principal causa dos processos infecciosos em ovelhas e, geralmente, as infecções por esses patógenos persistem durante o período seco, causando mastite na próxima lactação (POUTREL, 1984). BURRIEL (1997) comprovou que SCN provoca sérios danos aos tecidos da glândula mamária.
Tabela 6 - Bactérias isoladas em leite de ovelhas Santa Inês

\begin{tabular}{ll}
\hline $\mathrm{N}^{\mathrm{o}}$ de amostras de leite avaliadas & 125 \\
\hline $\mathrm{N}^{\mathrm{o}}$ amostras com crescimento & $27(21,6 \%)$ \\
Staphylococcus coagulase negativo & $64,3 \%$ \\
Staphylococcus coagulase positivo & $17,9 \%$ \\
Staphylococcus aureus & $3,6 \%$ \\
Streptococcus spp. & $3,6 \%$ \\
Coliformes & $10,7 \%$ \\
\hline
\end{tabular}

Domingues; LeITE (2005) relataram queem ovelhas criadas em confinamento aumenta a prevalência da mastite subclínica, provavelmente relacionado à função dos cordeiros como vetores mecânicos transmissores de patógeno de ovelhas infectadas para ovelhas sadias. Aconselha-se o confinamento das ovelhas e seus cordeiros durante o período de lactação, ou já no terço final da gestação, para evitar o problema da verminose no período periparto (BuENo et al., 2008). O aumento da concentração de ovelhas em espaço restrito no confinamento ou no semiconfinamento pode favorecer a transmissão da doença de glândulas mamárias contaminadas para outras sadias, através da boca do cordeiro, já que os cordeiros das ovelhas com mastite, que produzem menos leite, vão procurar mamar o leite de outras ovelhas, contaminando-as. PERSSON et al. (1996) comprovaram que a infecção intramamária em ovinos, geralmente, se dá do meio exterior para o interior da glândula, via cisterna do teto.

\section{CONCLUSÕES}

Dos 14 cordeiros que morreram dentro das duas primeiras semanas de vida, nove $(64,28 \%)$ poderiam ter sido salvos, se alguma medida tivesse sido tomada logo após o nascimento, como alimentá-los com leite integral de vaca três vezes ao dia, ou adotá-los em uma ovelha sadia. No entanto, tais medidas demandam mão-de-obra, nem sempre disponível na propriedade. O estudo mostra o impacto da mastite na mortalidade de cordeiros eno menor desempenho destes em um rebanho Santa Inês manejado de forma 
semi-intensiva, no qual as ovelhas ficam confinadas e semiconfinadas no período da lactação, o que pode aumentar a contaminação entre as matrizes. Os prejuízos gerados pela doença são grandes, já que incluem, ainda, os custos com medicamentos para tratamento das ovelhas afetadas, descarte, muitas vezes precoce, e depreciação zootécnica da matriz afetada pela doença, honorários de assistência técnica especializada, e aumento de mão-de-obra, gerado pela necessidade de aleitamento artificial de cordeiros. Esforços devem ser feitos no sentido de se estudar soluções para o controle da doença em rebanhos afetados.

\section{AGRADECIMENTOS}

À Fapesp pelo apoio financeiro ao projeto (Processo $\left.n^{\circ} 2007 / 56558-9\right)$.

\section{REFERÊNCIAS}

ALVAREZ, C.R.G.; DEL REI, A.J.; BARTOLOMEU, C.C.; BERGAMASCHI, K.B.; MACIEL, B.M. Ocorrência de mastite subclínica em ovelhas Santa Inês ao desmame criadas em dois sistemas de suplementação a pasto sob o clima tropical úmido. In: REUNIÃO ANUAL DA SOCIEDADE BRASILEIRA DE ZOOTECNIA, 44., Jaboticabal, 2007. Anais. Jaboticabal: Sociedade Brasileira de Zootecnia, 2007 (CD-ROM).

ARSENAULT, J.; DUBREUIL, R.H.; BÉLANGER, D. Risk factors and impacts of clinical and subclinical mastitis in commercial meat-producing sheep flocks in Quebec, Canada. Preventive Veterinary Medicine, v.87, n. 3/4, p. 373-393, 2008.

BARBOSA, D.A.; BLAGITZ, M.G.; KITAMURA, S.S.; GOMES, V.; BASTOS, C.R.; BINTES, N.R.; VERÍSSIMO, C.J.; MADUREIRA, K.M.; DELLA LIBERA, A.M.M.P. Comparação entre a contagem de células somáticas em leite de ovinos empregando técnicas direta e indireta. Arquivos do Instituto Biológico, São Paulo, v.71, p.384-387, 2004. Suplemento. Trabalho apresentado na REUNIÃO ANUAL DO INSTITUTO BIOLÓGICO, 17., 204, São Paulo. Resumo 203.

BERGONIER, D.; CRÉMOUX, R.; RUPP, R.; LAGRIFFOUL, G.; BERTHELOT, X. Mastitis of dairy small ruminants. Veterinary Research, v.34, p.689-716, 2003.

BLAGITZ, M.G.; RICCIARD, M.; FREITAS, C.; KITAMURA, S.S.; GOMES, V.; MADUREIRA, K.M.; DELLA LIBERA, A.M.M.P. Efeito do desmame na contagem de células somáticas (CCS) e exame microbiológico do leite de ovelhas. Arquivos do Instituto Biológico, São Paulo, v.71, p.381-383, 2004. Suplemento. Trabalho apresentado na REUNIÃO ANUAL DO INSTITUTO BIOLÓGICO, 17., 2004, São Paulo. Resumo 202.
BLAGITZ, M.G.; BENITES, N.R.; MELVILLE, P.A.; BATISTA, C.F.; RICCIARDI, M.; MANTOVINI, F.D.; GOMES, V.; ACEDO, M.R.; DELLA LIBERA, A.M.M.P. Importância do exame físico da glândula mamária no diagnóstico de mastite infecciosa em ovelhas da raça Santa Inês. Archives of Veterinary Science, v.12, p.175-176, 2007. Suplemento. Resumo 122.

BLAGITZ, M.G.; BATISTA, C. F.; SOUZA, F.N.; BENITES, N.R.; MELVILLE, P.A.; STRICAGNOLO, C.R.; RICCIARDI, M.; GOMES, V.; AZEDO, M. R.; SANCHES, B.G.S.; DELLA LIBERA, A.M.M.P. Perfil celular e microbiológico do leite de ovelhas Santa Inês no período lactante e pós-desmame. Pesquisa Veterinária Brasileira, v.28, n.9, p.417-422, 2008.

BOLSANELLO, R.X.; HARTMAN, M.; DOMINGUES, P.F.; JÚNIOR, A.S.M.; LANGONI, H. Etiologia da mastite em ovelhas Bergamácia submetidas à ordenha mecânica, criadas em propriedade de Botucatu, SP. Veterinária e Zootecnia, v.16, n.1, p.221-227, 2009.

BUENO, M.S.; VERÍSSIMO, C.J.; CUNHA, E.A.; SANTOS, L.E. O controle da verminose em sistema intensivo de produção de ovinos para abate. In: VERÍSSIMO, C.J. (Coord.), Alternativas de controle da verminose em pequenos ruminantes. Nova Odessa: Instituto de Zootecnia, 2008. p.35-50.

BURRIEL, A.R. Dynamics of intramammary infection in the sheep caused by coagulase-negative staphylococci and its influence on udder tissue and milk composition. Veterinary Record, v.140, n.16, p. 419-423, 1997.

BURRIS, M.J.; BAUGUS, C.A. Milk consumption and growth of suckling lambs. Journal of Animal Science, v.14, p.186-191, 1955.

CONTRERAS, A., SIERRA, D.; SÁNCHEZ A.; CORRALES, J.C.; MARCO, J. C.; PAAPE, M. J.; GONZALO, C. Mastitis in small ruminants. Small Ruminant Research, v.68, p.145-153, 2007.

COUTINHO, D.A.; COSTA, J.N.; RIBEIRO, M.G.; TORRES, J.A. Etiologia e sensibilidade antimicrobiana in vitro de bactérias isoladas de ovelhas da raça Santa Inês com mastite subclínica. Revista Brasileira de Saúde e Produção Animal, v.7, n.2, p.139-151, 2006.

CRUZ, M.; SERRANO, E.; MONTORO, V.; MARCO, J.; ROMEO, M.; BASELGA, R.; ALBIZU, I.; AMORENA, B. Etiology and prevalence of subclinical mastitis in the Manchega sheep at mid-late lactation. Small Ruminant Research, v.14, p.175-180, 1994.

DOMINGUES, P.F.; LEITE, C.A. Mastite em ovinos. $O$ Berro, n.73, p.50-60, 2005.

FERREIRA, M.I.C.; LIMA, MACEDO JÚNIOR, G.L.; BORGES, I.; VIANA, M. H.; COUTO, J.R.L.; CAVALCANTI, L.F.L. Efeito do número de fetos e do manejo nutricional sobre a produção de leite de ovelhas da raça 
Santa Inês. In: REUNIÃO ANUAL DA SOCIEDADE BRASILEIRA DE ZOOTECNIA, 44., Jaboticabal, 2007. Anais. Jaboticabal: Sociedade Brasileira de Zootecnia, 2007. (CD-ROM).

FERNANDES, J.C.T.; CARDOSO, M.R.I. Mamite ovina causada por Staphylococcus aureus. Primeira observação no Brasil. Arquivos da Faculdade de Veterinária UFRGS, v.13, p.71-74, 1985.

FTHENAKIS, G.C.; JONES, J.E. The effect of experimentally induced subclinical mastitis on milk yield of ewes and on the growth of lambs. British Veterinary Journal, v.146, n.1, p.43-49, 1990.

GONZALO, C.; ARIZNABARRETA, A.; CARRIEDO, J. A.; PRIMITIVO, F. S. Mammary pathogens and their relationship to somatic cell count and milk yield losses in dairy ewes. Journal of Dairy Science, v.85, p.1460-1467, 2002.

HARMON, R.J.; EBERHART, R.J.; JASPER, D.E.; LAN-GLOIS, B.E.; WILSON, R.A. Microbiological Procedures for the Diagnosis of Bovine Udder Infections. Arlington: National Mastitis Council, 1990. 34p.

HENDY, P.G.; PUGH, K.E.; HARRIS, A.M.; DAVIES, A. $\mathrm{M}$. Prevention of post weaning mastitis in ewes. Veterinary Research, v.109, n.3, p.56-57, 1981.

HERNANDES, G.S.; LUCHEIS, S.B. Monitoramento microbiológico da mastite ovina na região de Bauru (SP). O Biológico, São Paulo, v.68, p.5, 2006. Suplemento. Trabalho apresentado na REUNIÃO ANUAL DO INSTITUTO BIOLÓGICO, 19., 2006, São Paulo. Resumo $010 / 249$.

HOLT, J.G; KRIEG, N.R.; SNEATH, P.H.A.; STALEY, J.T.; WILLIAMS, S.T. Gram-positive cocci. In: STALEY, J.T. (Ed.). Bergey's manual of determinative bacteriology. 9.ed. Baltimore: Williams \& Wilkins, 1994. p.544-551.

HUESTON, W.D.; BONER, G.J.; BAERTSCHE, S.L. Intramammary antibiotic treatment at the end of lactation for prophylaxis and treatment of intramammary infections in ewes. Journal of the American Veterinary Medical Association, v.194, n.8, p.1041-1044, 1989.

JONES, J.E.T.; LANYON, M. An investigation of the incidence and causes of mastitis in ewes in lowland flocks. The Sheep Farmer, v.53, p.9-10, 1990.

KEISLER, D.H.; ANDREWS, M.L.; MOFATT, R.J. Subclinal mastitis in ewes and its effect on lambs performance. Journal of Animal Science, v.70, p.1677-1681, 1992.

KONEMAN, E.W.; ALLEN, S.D.; JANDA, W.M.; SCHRECKENBERGER, P.C.; WINN JR, W.C.W. Diagnóstico microbiológico - Texto e atlas colorido. 5.ed. Rio de Janeiro: Medsi, 2001. 1465p.
LARSGARD, A.G.; VAABENOE, A. Genetic and environmental causes of variation in mastitis in sheep. Small Ruminant Research, v. 12, p. 339-347, 1993.

MADEL, A.J. Observations on the mammary glands of culled ewes at the time of slaughter. Veterinary Record, v. 109, p. 363-363, 1981.

MELO, C.B.; ALMEIDA, B.M.; OLIVEIRA, A.A.; AZEVEDO, H.C.; MELO, L.S.S.; MATA, S.S. Avaliação de uma metodologia profilática contra a mastite clínica em ovelhas da raça Santa Inês. Arquivo Brasileiro de Medicina Veterinária e Zootecnia, v.60, n.4, p.1011-1013, 2008.

MEXIA, A.A.; MACEDO, A.F.; ALCAIDE, C.R.; SAKAGUTI, E.S.; MARTINS, E.N.; ZUNDT, M.; YAMAMOTO, S.M.; MACEDO, R.M.G. Desempenho reprodutivo e produtivo de ovelhas Santa Inês suplementadas em diferentes fases da gestação. Revista Brasileira de Zootecnia, v.33, n.3, p.658-667, 2004.

MEXIA, A.A.; MACEDO, F.A.F.; MACEDO, R.M.G.; SAKAGUTI, E.S.; SANTELLO, G.A.; CAPOVILLA, L.C.T.; ZUNDT, M.; SASA, AYA. Desempenho e características das fibras musculares esqueléticas de cordeiros nascidos de ovelhas que receberam suplementação alimentar em diferentes períodos da gestação. Revista Brasileira de Zootecnia, v.35, n.4, p.1780-1787, 2006. Suplemento.

NUNES, G.R.; BLAGITZ, M.G.; FREITAS, C.B.; SOUZA, F.N.; RICCIARDI, M.; STRICAGNOLO, C.R.; SANCHES, B.G.S.; AZEDO, M.R.; SUCUPIRA, M.C.A.; DELLA LIBERA, A.M.M.P. Avaliação de indicadores inflamatórios no diagnóstico da mamite ovina. Arquivos do Instituto Biológico, São Paulo, v.75, n.3, p.271-278, 2008.

OLIVEIRA, L.G.L.; ALMEIDA, M.Z.P.R.B.; AFONSO, J.A.B.; LÁZARO, N.S.; MENDONÇA, C. L. Aspectos clínico-epidemiológicos e etiológicos da mastite clínica em ovelhas da raça Santa Inês no agreste meridional do Estado de Pernambuco. Archives of Veterinary Science, v.12, p.124-125, 2007. Suplemento. Resumo 088.

OLIVEIRA, V.L.M. Aspectos do leite e mastite em ovinos da raça Santa Inês em Sergipe. 2006. 70f. Dissertação (Mestrado) - Universidade Federal de Sergipe, São Cristóvão, 2006.

PERSSON, K.; COLDITZ, I.G.; FLAPPER, P.; FRANKLIN, N.A.F.; SEOW, H.F. Cytokine-induced inflammation in the ovine teat and udder. Veterinary Immunology and Immunopathology, v.53, p.73-85, 1996.

POUTREL, B. Udder infection of goats by coagulasenegative staphylococci. Veterinary Microbiology, v. 9, p. 131-137, 1984.

RICCIARDI, M.; BATISTA, C.F.; BLAGITZ, M.F.; BENITES, N.R.; STRICAGNOLO, C.R.; ACEDO, M. R.; DELLA LIBERA, A.M.M.P. Avaliação do exame 
microbiológico para o diagnóstico de alterações mamárias em ovinos da raça Santa Inês criados no Estado de São Paulo. Archives of Veterinary Science, v.12, p.129-130, 2007. Suplemento. Resumo 091.

RODA, D.S.; SANTOS, L.E.; CUNHA, E.A. Peso ao nascer e mortalidade pré-desmame em cordeiros das raças Ideal e Corriedale. Boletim da Indústria Animal, v.52, n.1, p.67-70, 1995.

SANTOS, R. A cabra e a ovelha no Brasil. Uberaba: Agropecuária Tropical, 2003. 479p.

SANTOS, R.A.; MENDONÇA, C.L.; AFONSO, J. A.B.; SIM, L. C.V. Aspectos clínicos e características do leite em ovelhas com mastite induzida experimentalmente com Staphylococcus aureus. Pesquisa Veterinária Brasileira, v.27, n.1, p.6-12, 2007.

SARATSIS, P.; ALEXOPOULOS, C.; TZORA, A.; FTHENAKIS, G. C. The effect of experimentally induced mastitis on the milk yield of dairy ewes. Small Ruminant Research, v.32, p.205-209, 1999.

SCHALM, O.W.; NOORLANDER, D.O., Experiments and observations leading to development of the California Mastitis Test. Journal of the American Veterinary Medicine Association, v.130, n.5, p.199-207, 1957.

TORRES-HERNANDEZ, G.; HOHENBOKEN, W.

Relationships between ewe milk production and composition and preweaning lamb weight gain. Journal of Animal Science, v.50, n.4, p.597-603, 1980.
VAZ, A.K. Mastite em ovinos. A Hora Veterinária, v.16, n.93, p.75-78, 1996.

VERÍSSIMO, C.J.; BALDASSI, L.; HELLMEISTER, Z.M.M.; CORTEZ, D.H.; KOZUKI, F. T.; OTUKI, A.K.; BINUESA, F. Prevalência e prejuízos da mastite em um rebanho ovino. In: CONGRESSO BRASILEIRO DE MEDICINA VETERINÁRIA, 30., 2003, Manaus, AM. Anais. Manaus: Sociedade Brasileira de Medicina Veterinária, 2003. Resumo 004.

VERÍSSIMO, C.J.; CUNHA, E.A.; BUENO, M.S.; SANTOS, L.E. Sistema intensivo de produção de ovinos. Agropecuária Caterinense, v.15, n.3, p.37-41, 2002.

VERÍSSIMO, C.J.; NASSAR, A.F.C.; RODRIGUES, A.D.; KATIKI, L.M.; BUENO, M.S. Mastite em ovelhas primíparas em rebanho sob manejo intensivo. O Biológico, v.69, n.2, p.125, 2007.

WINTER, A. Mastitis in ewes. In Practice, v.23, n.3, p.160-163, 2001.

ZAFALON, L.F. Mastite subclinica bovina por Staphylococcus aureus: qualidade e quantidade de leite secretado por quartos tratados e não tratados e relação custo/benefício do tratamento durante a lactação. 2003. 66p. Tese (Doutorado) - Faculdade de Ciências Agrárias e Veterinárias, UNESP, Câmpus de Jaboticabal, Jaboticabal, 2003.

Recebido em $1 / 4 / 10$

Aceito em 29/10/10 